JIPFRI, Vol. 2 No. 1

Halaman: 43-48

Mei 2018
JIPFRI (Jurnal Inovasi Pendidikan Fisika dan Riset IImiah)

DOI: 10.30599/jipfri.v2i1.160

\title{
Pengukuran Koefisien Muai Volume Minyak Nabati dan Air Berdasarkan Relasi Linear Antara Perubahan Volume dan Perubahan Temperatur
}

\author{
Meta Yantidewi ${ }^{\star}$, Tjipto Prastowo, dan Alimufi Arief \\ Jurusan Fisika FMIPA Universitas Negeri Surabaya \\ Gedung C3 Kampus Ketintang Unesa, Surabaya 60231 \\ ‘E-mail: metayantidewi@unesa.ac.id
}

\begin{abstract}
Abstrak
Penelitian ini bertujuan untuk menentukan koefisien muai volume minyak nabati dan air sebagai cara efektif untuk mempelajari perilaku zat cair bila dipanaskan. Minyak nabati dalam penelitian ini adalah minyak goreng belum terpakai merek Filma, sedangkan air yang digunakan dalam penelitian ini adalah air distilasi. Instrument utama penelitian adalah dilatometer yang bekerja berdasarkan prinsip pemuaian zat cair. Metode penelitian mengadopsi metode peneliti terdahulu, dimana percobaan pemuaian volume zat cair dilakukan dalam dua tahap untuk masingmasing zat cair (dalam hal ini minyak nabati dan air). Tahap pertama adalah memanaskan zat cair secara tidak langsung melalui panas yang diserap dan didistribusikan oleh sejumlah air dalam bejana pemanas. Pada tahap kedua, sumber panas dihentikan dan zat cair dibiarkan terus mengalami pemuaian volume akibat kenaikan temperatur sebelum akhirnya mengalami kontraksi volume akibat penurunan temperatur. Pada saat proses pendinginan berlangsung, pengamatan dan pencatatan data panjang kolom zat cair dalam pipa kaca sebagai fungsi temperatur dilakukan. Berdasarkan data tersebut, perubahan volume zat cair akibat proses pendinginan dapat diestimasi. Dengan memanfaatkan relasi linier antara perubahan volume dan perubahan temperatur, diperoleh koefisien muai volume minyak nabati dan air berturut-turut sebesar $(7,2 \pm 0,2) \times 10^{-4} /{ }^{0} \mathrm{C}$ dan $(3,2 \pm 0,2)$ x $10^{-4 / 0} \mathrm{C}$ dalam batas-batas ketelitian alat ukur yang digunakan dalam penelitian.
\end{abstract}

Kata kunci: Koefisien muai volume, minyak nabati, air distilasi, relasi linier.

\begin{abstract}
The objective of this research was to determine the volume expansion coefficient of vegetable oil and water as the effective way to study the fluids' properties when they are heated. The vegetable oil used in this research is the unused vegetable oil of Filma, while the water used in this study is distilled water. The main instrument in this study is the dilatometer which works based on the principle of fluids expansion. The research methods adopted the methods of the previous researchers, in which the experiment of fluids volume expansion had been conducted in two stages for each fluids (in this case, the fluids were vegetable oil and water). The first stage was heating fluids indirectly through absorbed and distributed heat by an amount of water inside the boiling jug. In the second stage, the heat source was stopped and fluids were allowed to continue expanding in volume due to the rising temperature before the fluids finally experiencing volume contraction due to the decrease in temperature. When the cooling process was carried out, observation and recording of data of fluid column length in glass pipe as a function of temperature were held. Based on those data, the changes in fluids volume due to the cooling process could be estimated. By utilizing the linear relation between volume change and temperature change, the volume expansion coefficient values of vegetable oil and water were $(7,2 \pm 0,2) \times 10^{-4} / 0 \mathrm{C}$ and $(3,2 \pm 0,2) \times 10^{-4} /{ }^{\circ} \mathrm{C}$ within the limits of the accuracy of the measuring instrument used in the study.
\end{abstract}

Keywords: Coefficient expansion volume, vegetable oil, distilled water, linear relation.

\section{PENDAHULUAN}

Menurut Tippler dan Mosca (2008), ketika suatu zat menyerap panas atau kalor maka sifat fisis zat tersebut juga turut berubah. Sebagai contoh, perubahan temperatur suatu zat (baik zat padat, cair, maupun gas) 
umumnya diikuti oleh ekspansi atau kontraksi zat tersebut.

Ketika suatu zat mengalami pertambahan temperatur, maka zat tersebut dikatakan mengalami pemuaian. Young dalam Atmoko (2008) menjelaskan bahwa pemuaian atau ekspansi termal merupakan perubahan ukuran suatu zat akibat adanya perubahan temperatur. Selain itu, dikatakan pula jika pemuaian dipengaruhi oleh beberapa faktor seperti: volume awal zat, perubahan temperatur, dan koefisien muai zat.

Pemuaian fluida (zat cair dan zat gas) berbeda dengan pemuaian zat padat. Jika pada pemuaian zat padat terdapat tiga parameter pemuaian yakni, pemuaian panjang, luas, dan volume, maka pada pemuaian fluida hanya terdapat satu parameter pemuaian yakni pemuaian volume. Hal ini dapat dimengerti karena fluida baik zat cair maupun zat gas selalu menempati wadah dari bahan padat dengan volume tertentu. Apabila wadah yang berisi zat cair dipanaskan maka wadah tersebut mengalami perubahan temperatur sehingga zat cair dalam wadah akan ikut mengalami perubahan temperatur.

Penelitian ini merupakan pengembangan dari penelitian oleh Rahmawati, Sucahyo, dan Supardi (2014), dimana zat cair yang digunakan saat itu adalah air distilasi. Penelitian ini menggunakan minyak nabati dan air distilasi sebagai subjek penelitian. Tujuan penelitian adalah menentukan koefisien muai volume minyak nabati dan air distilasi serta untuk membandingkan temuan dalam penelitian ini dengan temuan terdahulu dan nilai referensi sebagai salah satu cara efektif untuk mempelajari perilaku zat cair yang memiliki perbedaan viskositas jika dipanaskan.

\section{METODE/EKSPERIMEN}

Metode penelitian merupakan adopsi dari metode penelitian oleh Rahmawati, Sucahyo, dan Supardi (2014), dengan minyak nabati dan air distilasi sebagai zat cair yang akan ditentukan nilai koefisien muai volumenya. Zat cair dalam penelitian ini adalah minyak goring belum terpakai merek Filma dan air distilais. Instrumen utama dalam penelitian ini adalah dlatometer. Dilatometer ini bekerja berdasarkan prinsip pemuaian fluida cair (lihat Gambar 1).

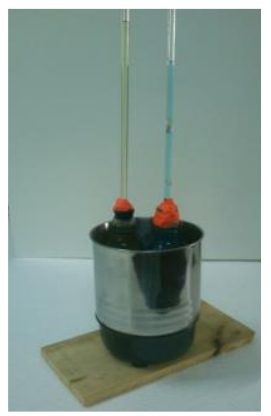

Gambar 1. Dilatometer

Percobaan pemuaian volume minyak nabati dalam penelitian ini dilakukan dalam dua tahap berurutan untuk masing-masing zat cair.

Pada tahap pertama percobaan pemuaian volume minyak nabati, dilatometer yang telah berisi minyak nabati dimasukkan ke dalam bejana pemanas berisi air tawar biasa dan termometer berskala. Dilatometer terdiri dari tabung gelas dan pipa kaca, dimana dimana bagian ujung atas tabung gelas ditutup dengan penutup terbuat dari bahan karet sehingga pipa kaca dapat berdiri tegak menancap pada bahan karet tersebut. Pemanasan minyak nabati dalam dilatometer secara tidak langsung, dimana dilatometer menyerap panas yang berasal dari air dalam bejana pemanas. Proses pemanasan berlangsung dari $30^{\circ} \mathrm{C}$ hingga $45^{\circ} \mathrm{C}$ selama beberapa menit.

Pada tahap kedua percobaan, sumber energi listrik dihentikan dan minyak nabati dibiarkan beberapa saat terus mengalami pemuaian volume sebagai akibat kenaikan temperatur, sebelum akhirnya mengalami kontraksi volume sebagai akibat penurunan temperatur. Ketika proses pendinginan berlangsung, dilakukanlah pengamatan dan pencatatan data terhadap panjang kolom minyak nabati dalam pipa kaca sebagai fungsi temperatur.

Kedua tahapan prosedur percobaan pemuaian minyak nabati tersebut juga diterapkan pada percobaan pemuaian air. Yang 
membedakan hanyalah temperatur selama pemanasan pada tahap pertama, dimana air distilasi dipanaskan pada temperatur $29^{\circ}-50^{\circ} \mathrm{C}$ selama beberapa menit.

Persamaan matematis yang digunakan untuk menentukan koefisien muai volume $\gamma$ minyak nabati dan air berasal dari pengamatan visual pemuaian volume, pengukuran perubahan volume $\Delta V$ dan perubahan temperatur $\Delta T$ berbentuk persamaan linier.

$$
\Delta V=\gamma V_{o} \Delta T
$$

dimana $V_{o}$ merupakan volume awal minyak nabati yang telah ditentukan terlebih dahulu dengan gelas ukur sebesar $V_{o}=147 \mathrm{~mL}$ pada temperatur ruang $T=28^{\circ} \mathrm{C}$ di Laboratorium Elektronika dasar dan Instrumentasi Jurusan Fisika, FMIPA Unesa.

Langkah penting lain dalam penelitian ini adalah mengambil zat cair dengan menggunakan pipa kaca dan mengukur panjang kolom zat cair dalam pipa kaca $(6,2$ $\mathrm{cm})$ sebelum memindahkannya dalam syringe. Volume minyak nabati yang terukur dalam syringe $(0,56 \mathrm{~mL})$ kemudian dibagi dengan panjang kolom zat cair dalam pipa kaca, maka diperoleh volume minyak nabati per satuan panjang dalam pipa kaca sebesar $0,090 \mathrm{~cm} / \mathrm{mL}$. Nilai ini penting digunakan sebagai faktor pengali dalam estimasi $\Delta V$.

Hubungan antara perubahan volume dan perubahan panjang kolom zat cair dalam pipa kaca adalah

$$
\Delta V=\pi r^{2} \Delta h
$$

dimana $r$ adalah jari-jari pipa kaca dan $\Delta h$ adalah perubahan panjang kolom zat cair dalam pipa kaca yang diukur selama proses pendinginan. Persamaan (2) di atas menceritakan kesebandingan antara $\Delta V$ dan $\Delta h$, bersama-sama dengan persamaan (1) menjadi kunci masalah penentuan $\gamma$.

\section{HASIL DAN PEMBAHASAN}

Berikut ini merupakan hasil yang telah diperoleh dalam penelitian ini beserta pembahasannya.
HASIL

Tabel 1 menyajikan data numerik perubahan temperatur minyak $\Delta T$, perubahan panjang kolom minyak $\Delta h$, dan perubahan volume minyak $\Delta V$ saat proses pendinginan, dimana pengamatan visual dan pencatatan dimulai dari temperatur $45^{\circ} \mathrm{C}$ sampai $30^{\circ} \mathrm{C}$.

Tabel 1. Data hasil percobaan minyak nabati

\begin{tabular}{cccc}
\hline$T\left({ }^{\circ} \mathrm{C}\right)$ & $\Delta T\left({ }^{\circ} \mathrm{C}\right)$ & $\Delta h(\mathrm{~cm})$ & $\Delta V(\mathrm{~mL})$ \\
\hline 45 & 15 & 13,5 & 1,39 \\
44 & 14 & 13,4 & 1,38 \\
43 & 13 & 13,1 & 1,35 \\
42 & 12 & 12,4 & 1,27 \\
41 & 11 & 11,6 & 1,17 \\
40 & 10 & 10,7 & 1,07 \\
39 & 9 & 9,7 & 0,95 \\
38 & 8 & 8,7 & 0,84 \\
37 & 7 & 7,6 & 0,71 \\
36 & 6 & 6,6 & 0,60 \\
35 & 5 & 5,6 & 0,48 \\
34 & 4 & 4,8 & 0,39 \\
33 & 3 & 4,0 & 0,30 \\
32 & 2 & 3,2 & 0,21 \\
31 & 1 & 2,2 & 0,09 \\
30 & 0 & 1,4 & 0
\end{tabular}

Jika Tabel 1 menyajikan data hasil percobaan minyak nabati, maka Tabel 2 di bawah ini menampilkan data numerik hasil percobaan air distilasi yang meliputi data perubahan temperatur air distilasi $\Delta T$, perubahan panjang kolom air distilasi $\Delta h$, dan perubahan volume air distilasi $\Delta V$ saat proses pendinginan.

Tabel 2. Data hasil percobaan air distilasi

\begin{tabular}{cccc}
\hline$T\left({ }^{0} \mathrm{C}\right)$ & $\Delta T\left({ }^{\circ} \mathrm{C}\right)$ & $\Delta h(\mathrm{~cm})$ & $\Delta V(\mathrm{~mL})$ \\
\hline 50 & 21 & 12,6 & 0,96 \\
49 & 20 & 12,6 & 0,96 \\
48 & 19 & 12,4 & 0,94 \\
47 & 18 & 12,1 & 0,91 \\
46 & 17 & 11,8 & 0,88 \\
45 & 16 & 11,3 & 0,84 \\
44 & 15 & 10,7 & 0,78 \\
43 & 14 & 10,1 & 0,73 \\
42 & 13 & 9,5 & 0,67 \\
41 & 12 & 8,9 & 0,61 \\
40 & 11 & 8,3 & 0,56 \\
39 & 10 & 7,8 & 0,51 \\
38 & 9 & 7,2 & 0,46 \\
37 & 8 & 6,6 & 0,40 \\
36 & 7 & 6,1 & 0,35 \\
35 & 6 & 5,5 & 0,30 \\
34 & 5 & 5,0 & 0,25 \\
33 & 4 & 4,5 & 0,20
\end{tabular}




\begin{tabular}{cccc}
\hline$T\left({ }^{0} \mathrm{C}\right)$ & $\Delta T\left({ }^{0} \mathrm{C}\right)$ & $\Delta h(\mathrm{~cm})$ & $\Delta V(\mathrm{~mL})$ \\
\hline 32 & 3 & 3,9 & 0,15 \\
31 & 2 & 3,5 & 0,11 \\
30 & 1 & 4,0 & 0,05 \\
29 & 0 & 2,3 & 0 \\
\hline
\end{tabular}

Pada percobaan air distilasi ini, rentang temperatur yang tercatat mulai dari temperatur $50^{\circ} \mathrm{C}$ hingga $29^{\circ} \mathrm{C}$. Mengingat bahwa air berwujud cair pada temperatur $0^{\circ} \mathrm{C}-100^{\circ} \mathrm{C}$ serta sifat anomali air pada temperatur $0^{\circ} \mathrm{C}-4^{\circ} \mathrm{C}$ seperti yang dinyatakan oleh Yoo dan Boyd (1994), maka variabel temperatur dalam percobaan pengukuran koefisien muai volume air distilasi ini sengaja diambil pada rentang $50^{\circ} \mathrm{C}$ hingga $29^{\circ} \mathrm{C}$

\section{PEMBAHASAN}

Berdasarkan data tabel 1 dibuat grafik perubahan volume $\Delta V$ terhadap perubahan temperatur $\Delta T$ (lihat Gambar 2).

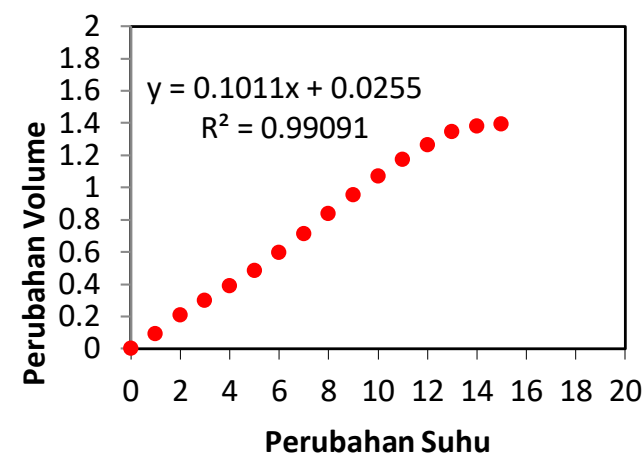

Gambar 2. Kurva hasil percobaan pemuaian volume minyak nabati

Terlihat kurva pada Gambar 2 tersebut hampir menyerupai garis lurus yang bisa dilihat baik secara visual maupun dibuktikan dari nilai $R^{2}=0,99091$ yang relatif mendekati nilai $R^{2}=1$ sebagai batas atas korelasi linear dua variabel. Bentuk kurva tersebut telah sesuai dengan prinsiap linearitas antara peubahan volume minyak nabati $\Delta V$ dan perubahan temperatur minyak nabati $\Delta T$, sepertin yang diprediksi oleh persamaan (1). Dengan demikian, kurva pada Gambar 2 cukup valid digunakan untuk menentukan secara akurat koefisien muai volume $\gamma$ minyak nabati. Dengan $V_{o}=140 \mathrm{~mL}$, maka diperoleh $\gamma$ untuk minyak nabati adalah sebesar $(7,2 \pm 0,2) \times 10^{-4} /{ }^{\circ} \mathrm{C}$ dalam batas-batas ketelitian alat-alat ukur yang digunakan dalam penelitian ini (mistar berskala $1 \mathrm{~mm}$ dan termometer berskala 1 derajat Celcius).

Jika 22 titik data pada Tabel 2 di atas dibuat grafik korelasi antara perubahan volume dengan perubahan temperatur, maka akan diperoleh bentuk grafik yang mendekati garis lurus (lihat Gambar 3).

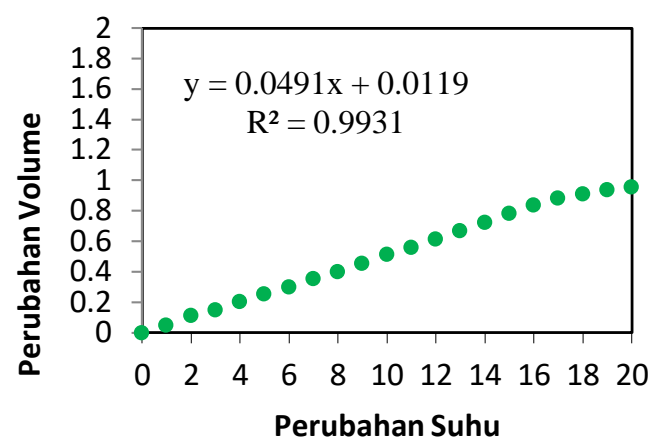

Gambar 3. Kurva hasil percobaan pemuaian volume air distilasi

Grafik pada Gambar 3 tersebut di atas memiliki $R^{2}=0,9931$ yang relatif mendekati $R^{2}=1$, batas atas koerelasi linear dua variabel. A curve curve fitting technique for a straight line yang diterapkan untuk 22 titik memberikan gradien garis lurus sebesar 0,0491 . Apabila persamaan (1) mengasumsikan relasi linear (berlaku saat pemanasan dan pendinginan) antara $\Delta V$ dan $\Delta T$, maka gradien sebesar itu adalah sama dengan $\gamma V_{o}$. Dengan $V_{o}=154 \mathrm{~mL}$, maka diperoleh $\gamma$ untuk air distilasi adalah sebesar $(3,2 \pm 0,2) \times 10^{-4} /{ }^{\circ} \mathrm{C}$ dalam batas-batas alat-alat ukur yang digunakan dalam penelitian ini (mistar berskala $1 \mathrm{~mm}$ dan termometer berskala 1 derajat Celcius).

Estimasi ketidakpastian hasil pengukuran sebesar $\pm 0,2$ diperoleh dari ketidakpastian pengukuran panjang kolom minyak nabati dalam pipa kaca yang dominan terhadap ketidakpastian pengukuran temperatur minyak nabati.

Temuan utama dalam penelitian ini, yaitu koefisien muai volume minyak nabati sebesar $\gamma=7,2 \times 10^{-4} /{ }^{\circ} \mathrm{C}$ pada temperatur ruang $30^{\circ} \mathrm{C}$ akan dibandingkan dengan hasil penelitian terdahulu, yakni Rahmawati, Sucahyo, dan Supardi (2014), serta Coupland dan McClements (1997), dan nilai referensi yang diberikan oleh Leaflets (n.d.) dan PHYWE. (n.d.). Literatur acuan fisika eksperimen 
Leaflets (n.d.) dan PHYWE. (n.d.) menyatakan bahwa nilai koefisien muai volume zat cair bergantung pada temperatur ruang dimana percobaan dilaksanakan. Selain itu, Boyd (2000) juga menyatakan bahwa temperatur air bergantung pada temperatur ruangan serta lokasi/tempat dimana air tersebut berada [8]

Pada temperatur $20^{\circ} \mathrm{C}$, PHYWE. (n.d.) melaporkan nilai koefisien muai volume air dan olive oil berturut-turut adalah sebesar 2,0 x 10${ }^{4} /{ }^{\circ} \mathrm{C}$ dan $7,2 \times 10^{-4} /{ }^{\circ} \mathrm{C}$, sementara Coupland dan McClements (1997) melaporkan bahwa nilai koefisen muai volume sunflower oil, corn oil, dan soy oil masing-masing ialah $6,61 \times 10^{-4} /{ }^{0} \mathrm{C}$, $7,22 \times 10^{-4} /{ }^{\circ} \mathrm{C}$, dan $7,24 \times 10^{-4} /{ }^{\circ} \mathrm{C}$. Temuan Rahmawati, Sucahyo, dan Supardi (2014) yang diperoleh dengan menggunakan metode pengukuran dan di tempat yang sama memberikan nilai koefisien muai volume air adalah sebesar $4,7 \times 10^{-4} /{ }^{\circ} \mathrm{C}$ pada temperatur $30^{\circ} \mathrm{C}$, tidak berbeda jauh dari referensi yang diberikan oleh Leaflets (n.d.) sebesar 4,9 x 10${ }^{4 / 0} \mathrm{C}$ pada temperatur yang sama. Apa yang dikemukakan oleh Coupland dan McClements (1997), PHYWE. (n.d.), serta Leaflets (n.d.) selaras dengan yang dinyatakan oleh Popiel dan Wojtkowiak (1998) bahwa nilai koefisien muai volume air bertambah seiring dengan pertambahan temperatur.

Dalam konteks temuan terdahulu oleh Rahmawati, Sucahyo, dan Supardi (2014), temuan utama dalam penelitian ini masuk akal mengingat minyak nabati lebih sensitif terhadap panas daripada air. Pengamatan selama percobaan juga menunjukkan bahwa minyak nabati lebih mudah mengalami perubahan volume saat pemanasan. Dalam konteks nilai referensi, koefisien muai volume sunflower oil, corn oil, soy oil, dan olive oil yang diberikan oleh PHYWE. (n.d.) serta Coupland dan McClements (1997) berturut-turut menunjukkan angka $6,61 \times 10^{-4} /{ }^{0} \mathrm{C}, 7,22 \times 10^{-}$ ${ }^{4} /{ }^{\circ} \mathrm{C}, 7,24 \times 10^{-4} /{ }^{0} \mathrm{C}$, dan $7,2 \times 10^{-4} /{ }^{\circ} \mathrm{C}$ pada $20^{\circ} \mathrm{C}$, sedangkan nilai koefisien muai volume minyak nabati yang ditunjukkan dalam penelitian ini yaitu sebesar $7,2 \times 10^{-4} /{ }^{\circ} \mathrm{C}$ pada $30^{\circ} \mathrm{C}$.

\section{PENUTUP}

Percobaan pemuaian termal minyak nabati dan air distilasi dengan menggunakan dilatometer yang berbasis relasi linear antara perubahan volume dan perubahan temperatur berhasil menemukan nilai koefisien muai minyak nabati dan air distilasi masing-masing sebesar $(7,2 \pm 0,2) \times 10^{-4} /{ }^{\circ} \mathrm{C}$ dan $(3,2 \pm 0,2) \times$ $10^{-4} /{ }^{\circ} \mathrm{C}$ pada $30^{\circ} \mathrm{C}$. Nilai ini konsisten dengan nilai referensi yang diberikan oleh PHYWE. (n.d.) utuk zat cair yang sejenis dan temuan penelitian terdahulu (Coupland dan McClements, 1997; Rahmawati, Sucahyo, dan Supardi, 2014). Temuan penelitian ini juga menguatkan kesimpulan bahwa zat cair yang cepat panas adalah zat cair yang memiliki koefisien muai volume yang lebih besar.

\section{UCAPAN TERIMAKASIH}

Tim penulis mengucapkan terimakasih kepada LPPM Universitas Negeri Surabaya atas hibah dana penelitian dalam penelitian dan pelaksanaan kegiatan pengabdian kepada masyarakat TA 2016. Tim penulis juga berterimakasih kepada Rahmawati dkk atas kontribusi berarti dalam bentuk diskusi penelitian terdahulu yang relevan serta petunjuk teknis percobaan pemuaian termal zat cair.

\section{DAFTAR PUSTAKA}

Atmoko, R. D. (2008). Penentuan koefisien ekspansi volume zat cair menggunakan metode pengukuran indeks bias zat cair (Skripsi Tidak Dipublikasikan). Program Studi Fisika Fakultas Sains dan Teknologi Uiversitas Sanata Dharma, Yogyakarta.

Boyd, C. E. (2000). Water quality: An introduction. Norwell, Massachusetts USA: Kluwer Academic Publishings.

Coupland, J. N \& McClements, D. J. (1997). Physical properties of edible oils. Journal of the American Oil Chemists' Society (JAOCS), 74(12), 1559-1564. doi:10.1007/s11746-9970077-1

Leaflets, L. P. (n.d.). Determining the volumetric expansion coefficient. In Heat Thermal 
48 | JIPFRI (Jurnal Inovasi Pendidikan Fisika dan Riset IImiah), Vol. 2 No. 1, Mei 2018

expansion Thermal expansion of liquids (pp. 1-4).

PHYWE. (n.d.). Thermal expansion in solids and liquids LEP 3.1.01. Germany: PHYWE series of publications.

Popiel, C. O., \& Wojtkowiak, J. (1998). Simple formulas for thermophysical properties of liquid water for heat transfer calculations (from $0 \mathrm{C}$ to $150 \mathrm{C}$ ). Heat transfer engineering, 19(3), 87-101.

Rahmawati, E., Sucahyo, I., Prastowo, T., Kusumawati, D. H., \& Supardi, Z. A. I. (2014). Meningkatkan kemampuan guru-guru IPA SMP di Sidoarho dalam pengembangan kit termodinamika sederhana untuk pembelajaran dengan pendekatan saintifik. , Prosiding Seminar Nasional Fisika 2014. Surabaya: Jurusan Fisika FMIPA Universitas Negeri Surabaya.

Tippler, P. A. \& Mosca, G. (2008). Physics for scientist and engineers with modern physics (6 $6^{\text {th }}$ edition). New York: W. H. Freeman \& Company.

Yoo, K. H. \& Boyd, C. E. (1994). Hydrology and water supply for pond aquaculture $\left(6^{\text {th }}\right.$ edition). Dordrecht: SpringerScience+Bussiness Media, B.V. 